\title{
Assessing the Viability of Quality Management in Organizations - A Retrospective and Prospective Overview with Reference to Pakistan
}

\author{
${ }^{1}$ Dr. Muhammad Asim, ${ }^{2}$ Dr. A. R. Zaki \\ ${ }^{2}$ Assistant Professor, Karachi University Business School, University of Karachi, University Road, Karachi- \\ 75270, Pakistan. \\ ${ }^{2}$ Chairman, Karachi University Business School, University of Karachi, University Road, Karachi-75270, \\ Pakistan.
}

\begin{abstract}
Quality management ( $Q M)$ is becoming a national priority strategy for most of the nations around the world and is gaining popularity at an ever increasing rate. Successful organizations around the globe are realizing the importance of quality management and embracing it as a proven technique that guarantees their own survival. QM has major technical, economical and human implications which influence the competitiveness, employment, exports and overall economic growth of any country. This research paper seeks to analyze the quality management practices in developing countries like Pakistan which requires giving much emphasis on the quality dimension. The paper attempts at analyzing the significance and willingness of business organizations regarding adoption and practice of quality management. This study also focuses to understand the ground reality of QM in Pakistani firms both public and private organizations. It is necessary to begin with asking that what quality we mean by quality management and its impact on productivity. In the past most of the national organizations showed an apprehension in adopting QM philosophy as they have a myopic view and were unable to realize its long term benefit. It is a fact that in comparison to the past the number of organizations that had acquired quality accreditation has obviously increased which is a clear indication that the awareness of this approach has been developed. Nevertheless the rate of embracing the concept of QM is still low as compared to our neighboring countries and other developed countries.
\end{abstract}

Keywords: Quality management, Quality assurance, Quality control, Quality attributes, Customer Satisfaction, Teamwork

\section{Introduction}

In the world economy today, competition is one of the most important factors in operating and running business. For almost every product or service there is more then one organization trying to compete it, so the solution to this problem lies in enticing customers through either innovation or modification but which is expected and accepted by the customer. This gives rise to the concept of quality aspect which will enable a firm to gain competitive edge and join the race with competitors. Price which indeed is a major factor but not the whole because if the cost of production of goods manufactured or services rendered is substantially significant a firm may not be competitive There are many other factors also but we shall focus and limit our discussion to the quality dimension only. This is an era where information technology and the modern and non traditional advertising and promotion techniques has enhanced and widened the knowledge horizons of today's customers and thus they demand quality products consistently that requires the proper development of strategies both at the corporate level and the functional level and is a key issue faced by managers. In this technological age quality is an international as well as a corporate concern. Superior products can enable a company to compete effectively in the global economy while low quality products can harm a firm and nation both at home and abroad and can have severe implications.

Quality is a common word in business language today, but without a common meaning. It is clear to a customer when he/she uses it. The problems are confronted with suppliers and manufacturers when they try to interpret the customer's meaning of good or bad quality. Different customers provide different ratings to the same product or service. They change their ratings with the passage of time. What used to be good quality yesterday may be seen today as poor. Moreover, the customer may still not like a product or service even though the manufacturer has produced it in accordance with his/her stated requirements. Like and dislikes in quality are also dependent on the unstated and even un-visualized expectations. A computer which was perceived to be of the highest quality only months ago may today be perceived as inadequate.

The word quality is not used in absolute terms. It is relative term which differs from person to person, country to country, and time to time. With such variations, it is difficult to provide good or excellent quality at all times, and for everyone. The life span of an organization in the open market is usually proportional to the 
time in which it can maintain the quality of its products and as services a good or excellent. As soon as the preferences of the customers change, due to relative improvements of some quality values of similar products produced by other supplier(s), the organization's decline is initiated. Quality is, therefore, a dynamic phenomenon and has a moving target.

The field of quality management emerged from metrology (measurement technology) about fifty years ago, when it was called quality control. Its theory has since been further built on concepts of statistics, operations management, economics, behavioral sciences, and religion. However, in most companies in developing countries including Pakistan, it is still being practiced within its narrow scope of mere metrology, and is being called quality control. In such companies, inspection and testing are the major contents of their quality control programs.

\section{Meaning of Quality, Attributes and Recognition}

Quality is of a product or service free of deficiencies or the characteristics of a product or service that satisfies customer needs. Generally the term quality is used to indicate fitness of a product or service for use. This definition seems to be too general. The term "fitness" may range from acceptable to highly acceptable. As the interest and importance of quality has become increasingly important, the meaning attributed to quality has become rigorous and strict. The American Society for Quality and Reliability (ASQR) views quality with strictness and defines it as "the totality of features and characteristics of a product or service that bear on its ability to satisfy given needs." Feigenbaum defines it as a way of managing the organization (Feigenbaum, 1991).

Quality products usually possess three characteristics: reliability, serviceability, and durability. Quality service means reliability, tangibles, responsiveness, assurance, and empathy.

To compete nationally and internationally, organizations are exhibiting a great deal of awareness, interest, and enthusiasm in quality and its improvement. In Europe one of the most commonly employed model is the EFQM Excellence Model which was launched in early 1992 as one of the guidelines in assessing organizations for the European Quality Award.

It is also to mention here that in the United States, the Malcolm Baldrige Quality Awards to top quality companies. The Malcolm Baldrige National Quality Award was set up in 1987 to recognize U.S. companies that excel in quality management. Companies winning this award indicate excellence in quality management by supporting and sustaining a culture that places quality in the very heart of the organization.

Most of the body of knowledge associated with the quality sciences was developed in the UK as design of experiments and in the US as statistical quality control. However Concern for quality is not just the domain of American or European quality movement. In the 1950s and 1960s, the Japanese industry focused and nurtured modern quality management. In the 1980s, the Japanese became preoccupied with quality and quality mania swept the nation and the concentration was on mirhyoku-teki hinshitsu (admirable and market-creating quality products and services). The Union of Japanese Scientists and Engineers (JUSE) was set up much prior to American efforts to promote quality.

It is worth mentioning that as a result of the contributions and interest generated by the Japanese, European and the American quality movements, the term "quality" has become a key concept and a common notion in many developing and developed countries across the world and more and more companies are going for quality certification to prove that their products and services are quality-worth.

\section{Importance of Quality}

Quality goods and services are strategically important to the company and to the country it represents. The quality of a firm's products, the prices it charges, and the supply it makes available are all factors that determine demand. The quality factor can affect a firm in four ways:

1. Company's reputation- an organization can expect its reputation for quality.

2. Costs and market share- improved quality can lead to increased market share and cost savings.

3. Product liability- organizations offering inferior quality products or services will be held responsible for any damage or injury that might result from its use.

4. International implications- for both a company and a country to compete effectively in the global economy its product must be of reasonable quality.

Since Quality Management focuses upon the continuous improvement in quality of the products or services, it is essential that the senior management must appreciate and realize its importance and institutionalize it in the organizational hierarchical system and make it an integral part of the management system. This necessitates that the concept of quality management must be cascaded down the organizational hierarchy accordingly and simultaneously at all levels and in all the involving organizational functional areas. 
Lack and negligence in this regard may result in the misuse of organizational resources and ultimately deviating from the track of success.

\section{Quality Control and Quality Management}

In order to understand further the concept of quality one should know the difference between total quality control and total quality management.

Total Quality Control (TQC) has been recognized as an important area of management and its impact in producing high quality and reliable products is significant. Many companies vying for the Malcolm Baldrige Quality Award have total quality control as an important agenda in their preparation.

TQC effort generates a great deal of interest among employees and ensures their active participation in producing quality products, After passing several stages in the quality process, many companies have come to realize the importance of Total Quality Control in modern business. Total Quality Control focuses on improvements in product quality, product design, the operational or production flow, the quality consciousness and efforts of employees, service quality, customer acceptance and satisfaction. The impact of TQC is generally reflected in operating costs, service costs, and product costs.

The entire process of managing total quality control is known as Total Quality Management (TQM), which includes quality-related activities related to various aspects from the conception of product stage through production and customer service.

Total quality management $(\mathrm{TQM})$ is an integrated organization-wide strategy for improving product and service quality (Fig. 1) TQM is not a specific tool or technique. Rather, TQM is a philosophy or overall approach to management that is characterized by three principles: customer focus and satisfaction, continuous improvement, and teamwork.

Fig.1 Illustrating scope of TQM

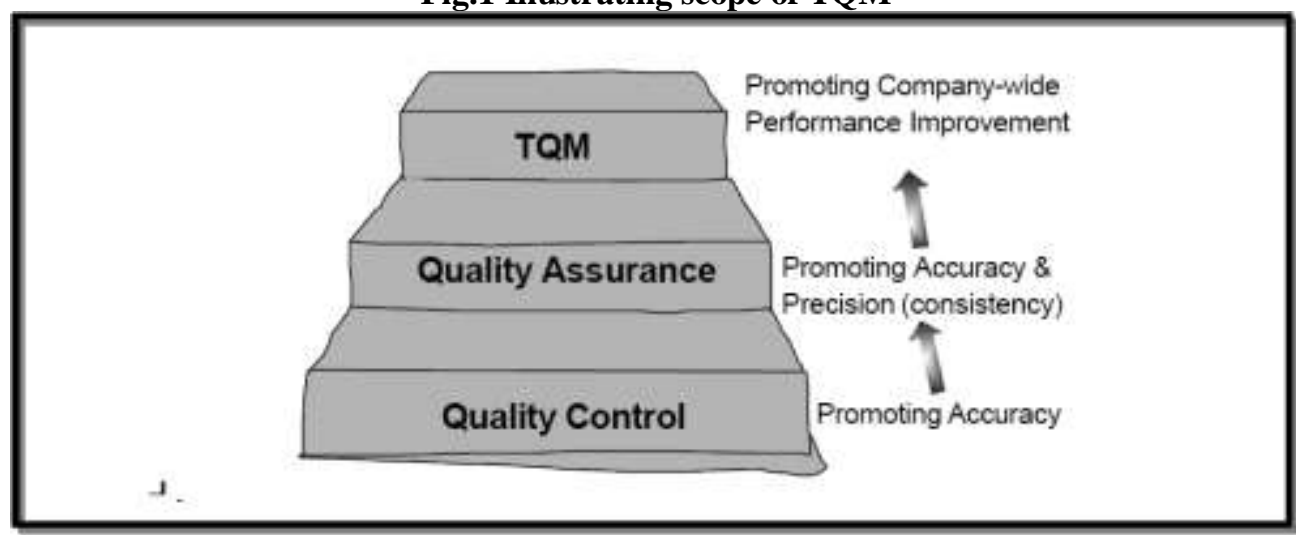

Customer focus means that the entire organization, from top to bottom, should be focused on meeting customers' needs. Customer satisfaction is an organizational goal to make products or deliver services that meet or exceed customers' expectations.

Continuous improvement is an ongoing commitment to increase product and service quality by constantly assessing and improving the processes and procedures used to create those products and services. TQM require continuous improvement in all processes, functions, departments and at all levels in a company and its associated partners. How do companies know whether they are achieving continuous improvement or not. Besides higher customer satisfaction, continuous improvement is usually associated with a reduction in variation. Variation is a deviation in the form, condition, or appearance of a product from the quality standard for that product. The less a product varies from the quality standard, or the more consistently a company's products meet a quality standard, the higher the quality.

The third principle of TQM is teamwork. Teamwork means collaboration between managers and non managers, across business functions, and between the company and its customers and suppliers. In short, quality improves when everyone in the company is given the incentive to work together and the responsibility and authority to use for improvements and solve problems.

Together, customer focus and satisfaction, continuous improvement, and teamwork mutually reinforce each other to improve quality throughout a company. Customer-focused continuous improvement is necessary to increase customer satisfaction. However, continuous improvement depends on teamwork from different functional and hierarchical parts of the company.

This research work also raises the question that as to how the company can grow and increase its share. To succeed in today's competitive market place a company must supply products and services in accordance with the customer's requirements and at minimum cost. To achieve this, the company must understand its role in 
the market place, organize itself to fulfill that role and ensure that all employees understand and are committed to fulfilling the customer's requirements.

TQM generally requires a change in the operational activities of an organization. It requires quality to be the first priority of every employee and for their efforts to be focused on prevention of errors. It is no longer sufficient to rely on the deflection and correction of errors. Every department, every activity, every person at every level, starting at the top of the organization, must be wholly converted to TQM.

"TQM is one of the most important management concepts which is central to the competitiveness and survival of organizations in the global market. In the words of Juran, (Juran, 1979) one of the gurus of the quality movement, "Total Quality Management is a major phenomenon of this age".

Feigenbaum (1991 p. 42) asserted, under the title "The market place; opportunity from quality leadership", that:

"Total quality control gives a producer major and unique competitive power in modern national and international marketplace. Moreover, it provides the company with the basis upon which to take suitable market leadership initiatives, as opposed to reacting defensively only to so-called consumerist pressure.

\section{TQM tools}

While discussing the quality paradox, one should know the various tools being used for quality control and quality management. Some of the commonly employed TQM tools are discussed below:

\section{Quality Circles}

This involve weekly meeting of the group of employees of similar work units. The group usually headed by their own supervisor consists of three to twelve people and the duration of the meeting ranges for about an hour in paid time. These people are trained to identify, analyze and solve problems in their own work, implementing the solution themselves whenever possible (APO, 1998).

\section{Kaizen and 5S}

Kaizen is based on people's commitment and participation by using their knowledge and experience, and can therefore be established through quality circles and/or suggestion schemes. It involves employees at all levels in quality improvements in their own work areas (Kanji and Asher, 1996).

$5 \mathrm{~S}$ is a combination of five Japanese words for a company-wide self-initiative program for: Cleanliness, Arrangement, Neatness, Discipline, and Order.

The National productivity Organization (NPO) established under the umbrella of the Ministry of Industries \& Production, Government of Pakistan, has recently launched "5S Good Housekeeping Japanese Standards Certification Program" under its "Productivity Vision 2012" (The News, 2009).

\section{Policy Deployment}

This is a systems-oriented process model for developing goal consensus throughout the organization. It develops short-term action plan (the means) at each level consistent with the overall strategy, by linking these plans to the measures derived from the policies (i.e. the objectives) established by the mangers. It is a highly participatory, vertical, top-down and bottom-up processes as the primarily coordinating/linking activity in the organization. It is also known as Hoshin Planning (Bounds and York, 1996).

\section{Benchmarking}

This compares once own practices with the best. It involves identification and feeling of gaps in performance by putting in place best practices, thereby establishing superior performance. Normally three types of benchmarking are done: (1) Internal, (2) Competitive, and (3) Comparative (Kanji and Asher, 1996).

\section{Re-Engineering}

This tool organizes the management to rethink, restructure and streamline the business structure, processes, methods of working, management systems and external relationships through which they create and deliver value (usually with the help of information technology).

\section{Seven Basic QC Tools}

These are the basic and fundamental statistical and analytical techniques and methods for data collection, analysis, and presentation in quality control and process control. This include: graphs, check sheets, pareto diagrams, histogram, scatter diagram, control charts, and cause-and-effect diagrams.

\section{Just-in-time Planning}

A production planning tool that delivers the raw materials or components to where they are required in the production line, to arrive just in time when they are needed. It uses a "Pull" system, whereby the material is 
Assessing the Viability of Quality Management in Organizations - A Retrospective and Prospective not received from the supplier or requested from the preceding production phase until it is needed to sustain production.

\section{Problems faced by Pakistani Organizations}

The business organizations in the world over are considered to be one of the important element on which the development of the country depends. To a great extent, the economic prosperity and growth of a country is reflected in the quality of its companies and their capability. The product that a company produces reflects its level of quality. There are many organizations in Pakistan at small and medium level that are reluctant in adopting quality management practice, for example the construction industry which despite of being one of the neglected sectors, participates to increase the GDP and comprises about $14 \%$ of the employment of the total labor force (Labor Force Survey Report- Government of Pakistan, 2005-06). On the other side in the manufacturing sector also there exist organizations that are termed as being backward and are sluggish in the relative use of the latest advances in technology, management styles and procedures.

The evolution of Quality in Pakistan can be divided into the following five eras (Moosa, 1994) (see Table 1).

Table 1 Quality eras in Pakistan

\begin{tabular}{|l|l|}
\hline 1947-1960s & $\begin{array}{l}\text { Craftsmanship, where quality was built into products but was successful only in low } \\
\text { production. }\end{array}$ \\
\hline 1960s-1970s & $\begin{array}{l}\text { Mass production started and large industries were setup. Quality control took the shape } \\
\text { of Inspection activity }\end{array}$ \\
\hline 1970s-1980s & Introduction of Statistical Quality/ Process Control in a few key industries \\
\hline 1980s-1990s & Introduction of Quality Circles \\
\hline 1990s & Introduction of Total Quality Management and ISO 9000 \\
\hline
\end{tabular}

Source: Moosa (1994)

Organization culture (shared values) becomes a special phenomenon and rises as a result of the cumulative effect of people equipped with the TQM tools, employees skills, successful teamwork which results in employees involvement, commitment, motivation and mobilization as shown in fig. 2. These companies utilize the best of their resources in establishing a conducive and encouraging environment for their employees at all levels. The main feature of these companies is that they do not focus only on single persons or single departments rather they involve all people and all departments at all levels. There are few companies in Pakistan that come under this category.

Technological advancements has profoundly change the way businesses operate in today's dynamic world. This had resultantly changed the management practices as well. Overwhelmed easier to understand dependence had inclined to management sciences and management practices. In today's world management sciences leads engineering (technological) sciences. Therefore it has gain widespread popularity. In the past managing organizations was restricted to a few variables of competitiveness which now has been changed into a huge set of ever changing and increasing number of complex variables. Thus today's management strategies of practices are persistently replacing old styles of management. The impact of IT cannot be ignored in making a large shift in business and management styles. In this regard total quality management is a subject that came into being and is now being practiced by many organizations to successfully handle these challenges and to acquire a competitive advantage in today's fierce and aggressive competitive world.

Taking the example of quality control this system is particularly weak in the government based organization of Pakistan. Among other reasons pertaining to different environmental factors / forces, one reason may be attributed to the fact that they have been traditionally operating in a monopolistic and hence noncompetitive state. Examples may be cited for universities, colleges, schools, ministries, civil services, utility supplier, law courts etc. The quality indicators other measurement systems feedback process evaluations for detecting loopholes are either weak or missing. On the contrary the manufacturing sector of industries witnesses a satisfactory application, however again its application in the services sector appears weak. It is to be noted that in case of manufacturing organization they emphasize on measuring the product quality but not the service quality. 


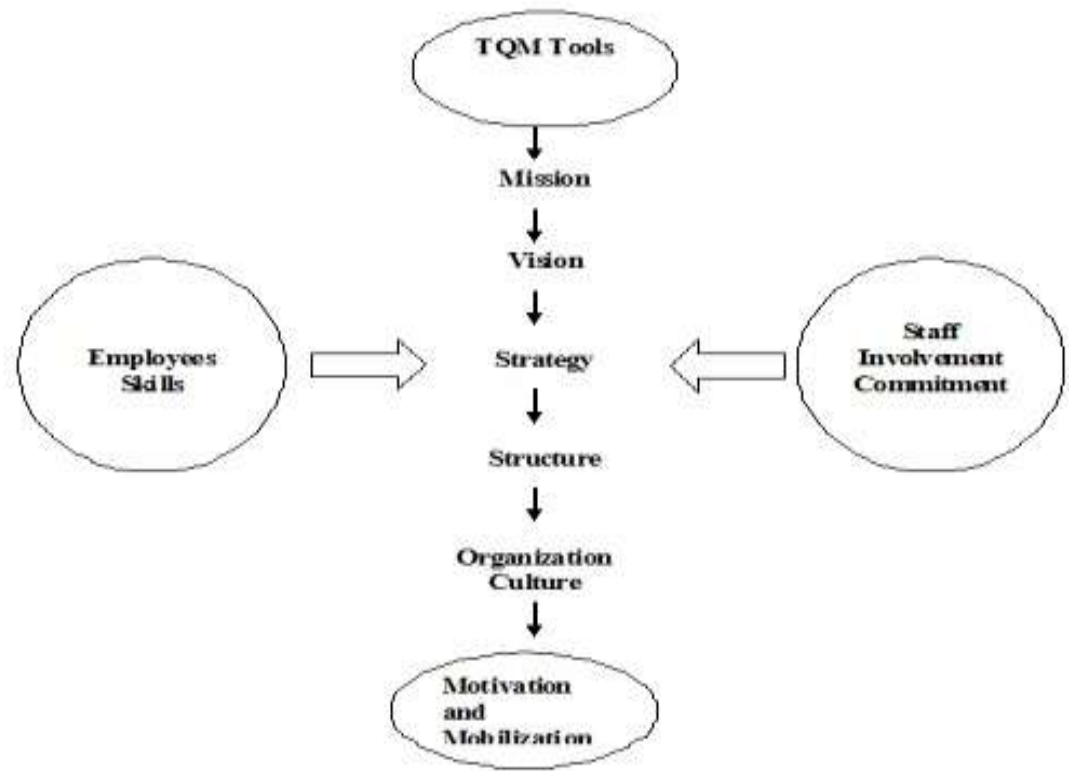

Fig. 2. Model of TQM adoption system by organizations

\section{Scenario of Organizations Operating in Pakistan with reference to Quality Management}

The intense competition of this dynamic age is responsible for dramatic and revolutionary transformations in organizations. The world is moving at a very rapid pace and has never witnessed such profound changes since the dawn of the industrial revolution. Organizations have to respond to these changes and adapt themselves to the prevailing circumstances. Thus the rate of meeting customer demand along with high quality and productivity standard is indeed an incredible challenge for successful organizations.

Quality and productivity go hand-in-hand, they are not mutually exclusive. Improvement in quality can lead to increased productivity and other benefits as shown in Table 2 .

Table 2 Gain in Productivity with Improved Quality

\begin{tabular}{lcc}
\hline Item & $\begin{array}{c}\text { Before } \\
\text { Improvement } \\
\mathbf{1 0 \%} \text { Nonconforming }\end{array}$ & $\begin{array}{c}\text { After } \\
\text { Improvement } \\
\mathbf{5 \%} \text { Nonconforming }\end{array}$ \\
\hline Relative total cost for 20 units & 1.00 & 1.00 \\
Conforming Units & 18 & 19 \\
Relative cost for nonconforming units & 0.10 & 0.05 \\
Productivity increase & & $(100)(1 / 8)=5.6 \%$ \\
Capability increase & & $(100)(1 / 8)=5.6 \%$ \\
Profit Increase & $(100)(1 / 8)=5.6 \%$ \\
\hline Adepre
\end{tabular}

Adapted from W. Edwards deming, Quality, Productivity and Competitive Position (Cambridge, Mass.: Massachussetts Institute of Technology, Center for Advanced Engineering Studies, 1982)

Thus any effort towards marketing, automation or improvement will prove useless if the quality is poor and it is worthwhile to note that quality is dictated by the customer. Thus the philosophy of continuous improvement from an organizational wide perspective that encompasses all the systems, processes and technology from top to bottom is referred to as Total Quality Management (TQM) as discussed earlier also.

TQM implementation requires a cultural change which is substantial in nature and cannot be accomplished in a short span of time nor are there any quick remedies for TQM to occur overnight. It takes particularly strong commitment and tolerance of the management to build the appropriate emphasis and techniques into the culture.

Since this is an age where every organization has been affected by the changes in the external environment. Organizations operating in Pakistan have also embraced this change which is essential for their survival in the face of globalization. Evidence to this fact can be observed from the dramatic rise in acquiring ISO certifications in comparison to the neighboring countries. With the exception of China and India the position of Pakistan is encouraging as illustrated in Table 3 below. 
Assessing the Viability of Quality Management in Organizations - A Retrospective and Prospective

Table 3: The Rising Trend of ISO 9001 certifications in Pakistan and its neighboring countries

\begin{tabular}{|c|c|c|c|c|c|}
\hline $\begin{array}{c}\text { Pakistan and } \\
\text { its } \\
\begin{array}{c}\text { Neighboring } \\
\text { Countries }\end{array}\end{array}$ & Dec.2004 & Dec.2005 & Dec.2006 & Dec.2007 & Dec.2008 \\
\hline Pakistan & 695 & 2013 & 2291 & 2580 & 2268 \\
\hline India & 12558 & 24660 & 40967 & 46091 & 37958 \\
\hline China & 132926 & 143823 & 162259 & 210773 & 224616 \\
\hline Afghanistan & 3 & - & 2 & 04 & 02 \\
\hline Iran & 3000 & 3090 & 5250 & 5503 & 7844 \\
\hline Bangladesh & 182 & 570 & 570 & 284 & 845 \\
\hline
\end{tabular}

Source: Adapted from The ISO Survey of Certifications 2008

According to the Annual Report 2011 of Securities Exchange Commission of Pakistan (SECP, 2011) the corporate sector of Pakistan consists of 59,417 corporations. Among these 53,750 are in private sector, 9878 are non-listed public and private corporations and 648 listed at Karachi Stock Exchange (KSE). Foreign companies account to 798 and public limited companies are 2855 in number. It is difficult to classify the organization operating in Pakistan with reference to the degree of implementation of quality management practices. There are the medium to small range organizations having a good quality culture. Some poor performing organizations may have a few high-level quality characteristics and vice versa. Thus as a whole it is inappropriate to say that the quality management practices is an inherited property of the large organization in particular the MNC'S.

A comparative study among National and Multinational Organizations of Pakistan conducted by Asim (2011) reveals that the National Organization were most of the time similar to Multinational Organizations in providing an organizational climate conducive to productivity and quality improvement. The underlying variables for this organizational climate were related to employee participation, communication, motivation, quality and technology standards along with the last variable as research and development (R\&D). Except R\&D where multinationals appeared to be leading the national Organizations all other parameters were mostly similar.

A related quality-based classification made by Moosa (1998) categorizes organization in four types. Firstly, No customer concern or zero level organizations that do not focus and emphasize upon their customer needs and requirements, these are mostly the state owned organization whose survival is guaranteed by the state.

The second type referred to as quality control or level one organization consider the laboratory testing of products as the key criteria of quality and consider it as the only role of quality control (QC) department. Their reaction is dependent and based solely upon the laboratory results.

The third category of companies defined as level II organizations is defined under the heading of Quality Assurance (QA) and includes organization that captures a broader view of the concept of quality and simultaneously incorporating it in various processes.

The last category of continual quality improvement is segmented into two levels of level III and level IV which further broadens the scope and involvement of quality program. Few organizations of Pakistan fall under level III while level IV includes the world-class global organizations where no organization in Pakistan belongs to this category.

\section{Evolution of Quality Concept}

A better understanding of the concept of QC and TQM can be achieved if the views of other prominent researchers and gurus are also examined. It will enable us to know the ground reality of quality, quality control and quality management in developing countries. Following are some of the suggestions proposed by various experts:

Since TQM is a continual activity it must be entrenched in the culture and communicated to all people in the organization. emphasis must be paid in improving customer perception of the product or service and not just on beating the competition or increasing market share; Training needs must be identified and eventually proper education and training will lead the employees to greater involvement and utilizing the most of their potentials. People must come to the work to perform their duties but also think on the dimension that how the existing work quality can be improved.

Total Quality Management requires a fundamental change in the way individuals and groups approach their work and their roles in the organization, from an environment of distrust and fear of reprisal to one of openness and trust where creativity can flourish. Such a change must break down departmental barriers. Managers must be seen as team leaders and coaches. Instead of concentrating power at the top, it must be shared with employees. The focus should be shifted from results to continuous improvement of the processes that produce results and long term goals must be considered as compared to short term goals and constancy of purpose must prevail. Organizational benefit and interest must be preferred over personal gains 

Scientific Management. Taylor (1911), who introduced time-and-motion study, came out with the idea of "one best way" of performing duties and tasks. While the supervisors planned the work, the workers carried out the assignments. Several of today's productivity improvement programs have roots in Taylor's scientific way of differentiating tasks and simplifying them. When tasks were simplified, the worker was responsible for only a specific and small aspect of the job. This resulted in few or zero defects, thus enhancing quality.

Dr W. Edwards Deming was another pioneer in the field of quality. With his statistical mathematics and physics background, he became an expert in applying statistical tools for improving quality. His work experience spans from Western Electric where Hawthorne studies were carried out to U.S. Secretary of War's office in the 1950s. While at the US. Bureau of Census, Deming (1982) developed sampling techniques. He had the distinguished honor of being invited by the Union of Japanese Scientists and Engineers (JUSE) to lecture on statistical quality control. Impressed by Deming's contribution, JUSE introduced Deming prize to recognize the quality efforts of individuals and Deming Application prize to recognize the quality efforts of companies. Deming's focus was on process control and process variation reductions. He advocated the use of statistical techniques in planning production and, exercising control in the production process. (Fig.3) Adequate statistical training must be given to workers to put statistical techniques into use.

Joseph Juran is another pioneer in the quality movement. Unlike Frederick Taylor, Juran approaches quality in an integrated manner and focuses on quality planning, quality control, and quality improvements. In his view, top management must bear the responsibility for quality and not the people at the operative level. Like Deming, Juran also contributed to Japan's efforts to manage quality. Juran (1980) quality philosophy encourages managers to examine the entire operational process to identify problems, starting from suppliers to customers and then prepare workers through training to do the same. The type of training Juran advocates includes group problem solving, brainstorming, group dynamics and teamwork. The purpose of such training is to identify cause-and-effect relationships (Fig.4).

Another quality guru is Philip Crosby whose book Quality is Free is a valuable contribution to the quality movement. Crosby's focus is on the cost aspect of quality. Crosby's work experiences at International Telephone and Telegraph Company (ITT) where he rose from a line inspector to Vice President provided a base for developing his ideas on quality. His ideas on quality led in vast savings for ITT. According to Crosby (1984) performance can be measured by cost of quality. Savings resulting from cost efficiency and effectiveness can be utilized for other purposes such as increased investments in new machinery and equipment and hiring additional workforce. His programs advocated at ITT include accounting for costs of scrap and waste, warranty, inspection, testing, rework, and so on.

Armand V. Feigenbaum's contributions are in the area of Total Quality Control (TQC). His interests in total quality control were generated while he was a student at M.I.T. in the early 1950s. Feigenbaum (1961) was critical of traditional and quality control programs because of their narrowness and limited application. Feigenbaum advocates for company-wide interdependent quality activities and measures which include the functional areas of marketing, engineering, shipping, operations, purchasing, and supervision of shop operations. In his book on Total Quality Control, he covers every aspect of total quality control and provides insights into the application of total quality control in a company. Because quality is critical for business success or failure, it should be treated as a major business strategic area.

Among the Japanese, Kaoru Ishikawa is considered as a pioneer in the quality movement. He was responsible for shifting quality focus from the monitoring and the controlling aspect of quality to the prevention of defective goods. He stresses the importance of education and training in quality focus. According to Ishikawa (1985), "there is a constant need to collect more information and develop better understanding about processes and their outcomes." (Fig.5).

Genichi Taguchi, a mechanical engineer who has won four Deming awards introduced the loss function concept, which combines cost, target and variation into one metric with specifications of being secondary importance, further he developed the concept of robustness which means that noise factors are taken into account to ensure that the system functions correctly. Noise factors are uncontrollable variables that can cause significant variability in the process or the product (Fig.6).

Thus it can be concluded that without the real support and commitment of top management, it is difficult to implement the productivity improvement programs. Employees must be prepared psychologically and physically as well before the start of any such program. Awareness of the need for and its importance should be created among the employees at all levels.

An overview of the quality eras from US to Japan and Japan to Europe is presented in the Table 4 below. 
Assessing the Viability of Quality Management in Organizations - A Retrospective and Prospective Table 4 Quality Era from US to Japan and Japan to Europe

\begin{tabular}{|c|c|c|}
\hline Era & Origin & Concept Proposed \\
\hline Early 1950’s & $\begin{array}{l}\text { Americans took the message of } \\
\text { quality to Japan }\end{array}$ & $\begin{array}{l}\text { W. Edward Deming } 14 \text { points and } \\
\text { PDCA (Plan, Do, Check, Act) } \\
\text { cycle (see Fig.2) } \\
\text { Joseph M. Juran } 10 \text { steps and } \\
\text { Quality Trilogy (see Fig.3) } \\
\text { Armand V. Feigenbaum TQC } \\
\text { (Total Quality Control) and } 3 \\
\text { steps to quality(Quality } \\
\text { Leadership, Modern Quality } \\
\text { Technology and organizational } \\
\text { Commitment) }\end{array}$ \\
\hline Late 1950 's & $\begin{array}{l}\text { Japanese developed new concepts } \\
\text { in response to the Americans }\end{array}$ & $\begin{array}{l}\text { Kaoru Ishikawa } 7 \text { basic quality } \\
\text { tools and Fish-bone diagram (see } \\
\text { Fig.4) } \\
\text { Genichi Taguchi proposed the } \\
\text { "Taguchi Methodology" (see } \\
\text { Fig.5) } \\
\text { Shigeo Shingo associated with } \\
\text { Just-in-Time manufacturing } \\
\text { inventor of SMED and Poka- } \\
\text { Yoke system. }\end{array}$ \\
\hline 1970's-1980's & $\begin{array}{l}\text { The western community followed } \\
\text { the Japanese industrial success }\end{array}$ & $\begin{array}{l}\text { Philip B. Crosby is known for the } \\
\text { concepts of "Quality is Free" \& } \\
\text { "Zero Defects". } \\
\text { Tom Peters identified leadership } \\
\text { as being central to the quality } \\
\text { improvement process, leadership } \\
\text { by proposed MBWA } \\
\text { (Management by walking about) } \\
\text { \& McKinsey 7-S framework (see } \\
\text { Fig.6) }\end{array}$ \\
\hline
\end{tabular}

Source: Developed by the authors

\section{Fig.3. Deming PDCA Cycle}

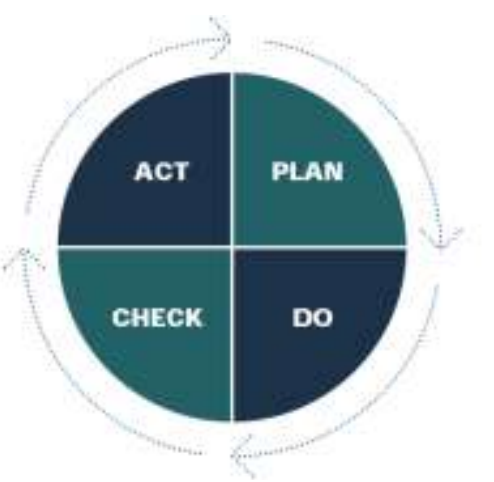

Plan what is needed

Do it

Check that it works

Act to correct any problems or improve performance

Source: www.dti.gov.uk/quality/gurus 


Quality Control Fig. 4. Juran Quality Trilogy

Source: $\underline{\text { www.dti.gov.uk/quality/gurus }}$

Fig.5. Ishikawa Fish-bone diagram



Source: $\underline{\text { www.dti.gov.uk/quality/gurus }}$

Fig.6. Taguchi Methodology



Source: www.dti.gov.uk/quality/gurus

\section{Conclusion}

Since TQM is concerned with continual improvements in all areas of work from high level to detailed execution of work at lower levels it leads to improvement in all aspects including people, processes, technologies and machine capabilities. TQM can be a powerful technique for unleashing employee creativity and potential, reducing bureaucracy and costs, and improving service to clients and the community.

The essence of TQM and its associated benefits can be drawn and enjoyed at its extreme if its prerequisites are analyzed cautiously and executed timely and properly. This includes a detailed analysis of the organization which is of course a critical responsibility of the top management. The organizations must be evaluated for its reactiveness and receptiveness in terms of its various characteristics such as responsiveness towards its internal and external environment, SWOT analysis, Employee-related characteristics such as employee morale, adaptation, communication, training needs etc. The financial position, administrative system and managerial capabilities must also be assessed and accounted for. In summary, the success of organization lies in designing developing and implementing the TQM program through smooth transition which requires certain level of stress, tolerance, time and cost.

As the organizations are growing and becoming more complex they are confronted with a more dynamic and competitive environment and to maintain its survival they must continuously respond to the environmental forces. However responding and ultimately reshaping organizational strategies accordingly can alone be insufficient until and unless performance criteria is not accounted for, thus it can be inferred that the future survival of organizations and especially the organizations that are operating in a country with high ripples in the economy like Pakistan need to focus on quality improvement to compete both locally and globally. 
Integrating TQM functions with the prevalent system of organizations is not an easy task for managers. In fact TQM implementation is a change that must be adapted and not adopted and the successful adaptation is possible by successful managers which requires devising mechanisms and which may involve some necessary and basic transformations and shifts in company policies and strategies for example organizational structure modification, changes in roles responsibilities and accountability, understanding meaning and importance of quality, employees involvement and dedication. Special all-staff meetings should also be conducted intermittently to generate and enrich ideas generation and hence encouraging a more participation of employees. An organization wide steering committee may be formed comprising of departmental heads to promote, oversee and co-ordinate the planning and implementation of TQM in all areas of operation because it is not similar to ISO 9000 program with a narrow agenda rather it is concerned with continual improvement in all areas of work including people, processes, technology and machine capabilities from high level to detailed execution of work at lower levels.

In summary, though TQM initially appears to be an unfulfilled dream, due to its complexity and comprehensiveness but there is nothing impossible. The senior management must adopt a strategic approach and leadership view that entails influencing employees intentionally but indirectly through their attitudes and actions and fostering a climate that make people feel the need for change and view it as a source of self-renewal and opportunities exploration.

\section{References}

[1] APO (1998), Implementing Quality Management in Asian and pacific Firms, Asian Productivity Organization, Japan.

[2] Asim, M. (2011) "A Comparative Study of Management Practices in Multinational and National Organizations of Pakistan", unpublished PhD Thesis, University of Karachi, Karachi, Pakistan.

[3] Bounds, G., York, L., Adams, M., and Ranney, G. (1996) "Beyond Total Quality Management", Singapore, McGraw-Hill.

[4] Crosby, P.B. (1984) Quality Without Tears, New York: McGraw Hill.

[5] Deming, W.E. (1982) Quality, Productivity and Competitive Position, Cambridge, MA: Massachusetts Institute of Technology.

[6] Feigenbaum, A.V. (1961) Total Quality Control, New York: McGraw Hill.

[7] Ishikawa, K. (1985) What is Total Quality Control? Englewood Cliffs, NJ: Prentice Hall.

[8] Juran, J.M.(1980) Quality Control Handbook, New York: McGraw Hill.

[9] Kanji, G.K. and Asher, M. (1996) “100 methods for Total Quality Management”, 1 st edn., UK: SAGE Publications

[10] Moosa, K. (1998) "Implementing Quality Management in Asian and Pacific Firms", Asian Productivity Organization, Japan.

[11] Moosa, K., Shariff, I. (1994) "Practical Guide to ISO 9000 Quality Management System", 1994, Lahore, Ibrahim Publishers.

[12] SECP (2011), Annual Report, Securities and Exchange Commission of Pakistan, Government of Pakistan, Pakistan.

[13] Taguchi, G. (1986) Introduction to Quality Engineering, Tokyo: Asian Productivity Organization.

[14] Taylor, F.W. (1911) Principles of Scientific Management, New York: Harper.

[15] The News, (2009) "New Methods to Boost Productivity Stressed", Karachi, The News, April 30 